\title{
Yeast Interactions in Inoculated Wine Fermentation
}

\author{
Maurizio Ciani ${ }^{1}$, Angela Capece ${ }^{2 *}$, Francesca Comitini', Laura Canonico', \\ Gabriella Siesto ${ }^{2}$ and Patrizia Romano ${ }^{2}$ \\ 'Dipartimento di Scienze della Vita e dell'Ambiente, Università Politecnica delle Marche, Ancona, Italy, ${ }^{2}$ Scuola di Scienze
Agrarie, Forestali, Alimentari ed Ambientali, Università degli Studi della Basilicata, Potenza, Italy
}

The use of selected starter culture is widely diffused in winemaking. In pure fermentation, the ability of inoculated Saccharomyces cerevisiae to suppress the wild microflora is one of the most important feature determining the starter ability to dominate the process. Since the wine is the result of the interaction of several yeast species and strains, many studies are available on the effect of mixed cultures on the final wine quality. In mixed fermentation the interactions between the different yeasts composing the starter culture can led the stability of the final product and the analytical and aromatic profile. In the present review, we will discuss the recent developments regarding yeast interactions in pure and in mixed fermentation, focusing on the influence of interactions on growth and dominance in the process.

OPEN ACCESS

Edited by:

Giuseppe Spano,

University of Foggia, Italy

Reviewed by:

Kiiyukia Matthews Ciira,

Mount Kenya University, Kenya

Roberto Foschino,

Università degli Studi di Milano, Italy

*Correspondence:

Angela Capece

angela.capece@unibas.it

Specialty section:

This article was submitted to

Food Microbiology,

a section of the journal

Frontiers in Microbiology

Received: 29 February 2016

Accepted: 04 April 2016

Published: 22 April 2016

Citation:

Ciani M, Capece A, Comitini F Canonico L, Siesto $G$ and Romano $P$ (2016) Yeast Interactions in Inoculated

Wine Fermentation.

Front. Microbiol. 7:555.

doi: 10.3389/fmicb.2016.00555
Keywords: Saccharomyces cerevisiae, non-Saccharomyces, yeast-yeast interactions, starter dominance, inoculated wine fermentation

\section{INTRODUCTION}

During the winemaking process, various microorganisms coexist and interact influencing the dominance, the persistence of fermenting yeasts and the analytical profiles of wine. Although the predominance of Saccharomyces cerevisiae on other genera is widely reported (Bisson, 1999; Bauer and Pretorius, 2000), few studies on the competition between species of the same genera (ArroyoLópez et al., 2011) and between strains of the same species (Barrajón et al., 2009; Capece et al., 2013; Perrone et al., 2013) are present in literature. On the other hand, as consequence of the reevaluation of the role of non-Saccharomyces yeasts, there is an increasing interest on the use of different species in mixed inoculated fermentation where the yeast interactions play a fundamental role. In this review, we will refer on the recent development regarding the dominance and yeast interactions in inoculated fermentations.

\section{S. cerevisiae/S. cerevisiae INTERACTIONS}

The use of S. cerevisiae as starter culture is the most widespread practice in winemaking. However, the inoculation of musts using selected Saccharomyces strains does not ensure their dominance at the end of fermentation (Capece et al., 2010). In fact, although possessing high competition, commercial strains do not completely inhibit wild strains until several days after the process has started. The starter culture should compete with not only non-Saccharomyces yeasts, but also with indigenous $S$. cerevisiae strains, which theoretically adapt better to must conditions (Barrajón et al., 2011; Capece et al., 2011). The knowledge of the mechanism(s) responsible for interaction among Saccharomyces strains could be of particular importance in understanding the 
observed persistence of these indigenous $S$. cerevisiae strains and the metabolic influence among $S$. cerevisiae strains composing mixed starter cultures. It has been hypothesized that S. cerevisiae strains can metabolically interact each other, by modifying fermentation products when grown in mixed culture. A compound, produced by a strain, could be taken up and used by other yeasts present. In this way, yeast interaction and sharing of metabolites could occur. Cheraiti et al. (2005) have demonstrated that redox interactions can occur between yeasts in co-culture, in particular acetaldehyde produced by one yeast was metabolized by the other. This observation provides an explanation as to why modulation of wine flavor in mixed culture cannot be replicated by blending wines together, as the modification arises from complex interactions, largely unknown until now, between strains included in mixed starters (Howell et al., 2006; King et al., 2008; Capece et al., 2013).

The competition degree of each strain is influenced by a number of abiotic factors ( $\mathrm{pH}$, temperature, ethanol, osmotic pressure, nitrogen, molecular sulfur dioxide, etc.) and biotic factors (microorganisms, killer factors, grape variety, etc.), which determine the capacity of one strain to out-compete another (Figure 1).

\section{Abiotic Factors}

Some winemaking practices, such as the amount of inoculum, rehydration conditions, or certain physical-chemical characteristics of the must, such as temperature, nutrients (nitrogen, vitamins; Rodriguez-Porrata et al., 2008), led to nonoptimal physiological conditions of the starter for competing with the wild biota, causing its growth inhibition by other strains better adapted to a specific oenological environment. Barrajón et al. (2010) evaluated the influence of oenological practices, strain vitality, stress tolerance, and nitrogen requirements on the starters implantation during industrial fermentations. The implantation of commercial strains was generally better in white musts than in red ones, probably in consequence of maceration practice, that might determine an increase of indigenous yeasts in must competing with the starter at the beginning of the fermentation. Different results were obtained: some commercial yeasts competed with one or several dominant wild strains, in other musts the inoculated yeast was completely displaced by only one wild strain at mid-fermentation, for some fermentations a wide variety of wild yeasts was found, none of them dominating the process. Vigentini et al. (2014) have investigated the evolution of the yeast populations during controlled fermentation of Chardonnay musts in two Italian wineries that used the same commercial strain. In the first winery, where the oenologist carefully managed only one starter culture and did not make any spontaneous fermentation, the commercial strain always mastered the process; conversely, in the second winery, where the oenologist performed also spontaneous fermentation, the starter culture did not even take over the dominance and a continuous succession of indigenous strains overcame without one prevailed on the others. Recently, some authors (Duarte et al., 2013) have hypothesized that some oenological additives, such as tannins and fermentation activators, can affect the starter implantation. García-Ríos et al.
(2014) carried out a preliminary approach in order to study the fitness advantages of four commercial wine yeast strains (PDM, ARM, RVA, and TTA) against some important oenological parameters, such as nitrogen concentration of grape must, fermentation temperature profile, and ethanol tolerance, which can exert strong stresses on the inoculated strain and determine its competitive advantage. A mathematical approach was used to model the hypothetical time needed for the control strain (PDM) to out-compete the other three strains in a theoretical mixed population. The theoretical values obtained were subsequently verified by competitive mixed fermentations in both synthetic and natural musts, which showed a good fit between the theoretical and experimental data. Specifically, the increase in nitrogen concentration and temperature values improved the fitness advantage of the PDM strain, whereas the presence of ethanol significantly reduced its competitiveness. However, the RVA strain proved to be the most competitive yeast for the three oenological parameters assayed.

Very little is known as fermentation temperature affects the dynamics of the Saccharomyces strain population. Torija et al. (2003) studied the influence of fermentation temperature (from 15 to $35^{\circ} \mathrm{C}$ ) on a mixed population of $S$. cerevisiae strains, by evaluating the competition during alcoholic fermentation, at different temperatures, as a tool for testing the natural endurance of indigenous strains. They demonstrated that the temperature of fermentation could clearly affect the development of the different Saccharomyces strains: some strains were predominant at low temperatures, whereas others predominated at high ones. The usual growth curve was observed at 25 and $30^{\circ} \mathrm{C}$, whereas at $35^{\circ} \mathrm{C}$ a high yeast mortality was found, which may have induced stuck fermentations with high residual sugar. In fact, these results agree with previous studies, reporting a decrease of yeast viability as the temperature increases (Casey et al., 1984), probably as a consequence of a greater accumulation of intracellular ethanol at higher temperatures, that determine cell toxicity and alter the structure of the membrane, decreasing its functionality (Lucero et al., 2000). On the contrary, at low temperatures there was no decline phase, but the stationary phase lasted until the end of fermentation. The percentage of the different Saccharomyces strains changed considerably during fermentation, probably in consequence of their sensitivity to ethanol toxicity. However, it is reported that the ethanol tolerance of some yeast species depends on the temperature (Gao and Fleet, 1988), and this could be the case also for some Saccharomyces strains. This may explain why the presence of some strains decreases at higher temperatures, but they are able to finish the fermentation at lower temperatures (Torija et al., 2003).

\section{Biotic Factors}

Ineffective starter implantation was also observed in some fermentation processes despite the use of correct winemaking practices. This means that other factors, i.e., biotic factors, like competition between microorganisms for space and nutrients, or production of toxic compounds (killer factors, medium-chain fatty acids, etc.), can affect starter dominance.

Among the biotic factors underlying the interactions between the different Saccharomyces strains during alcoholic 


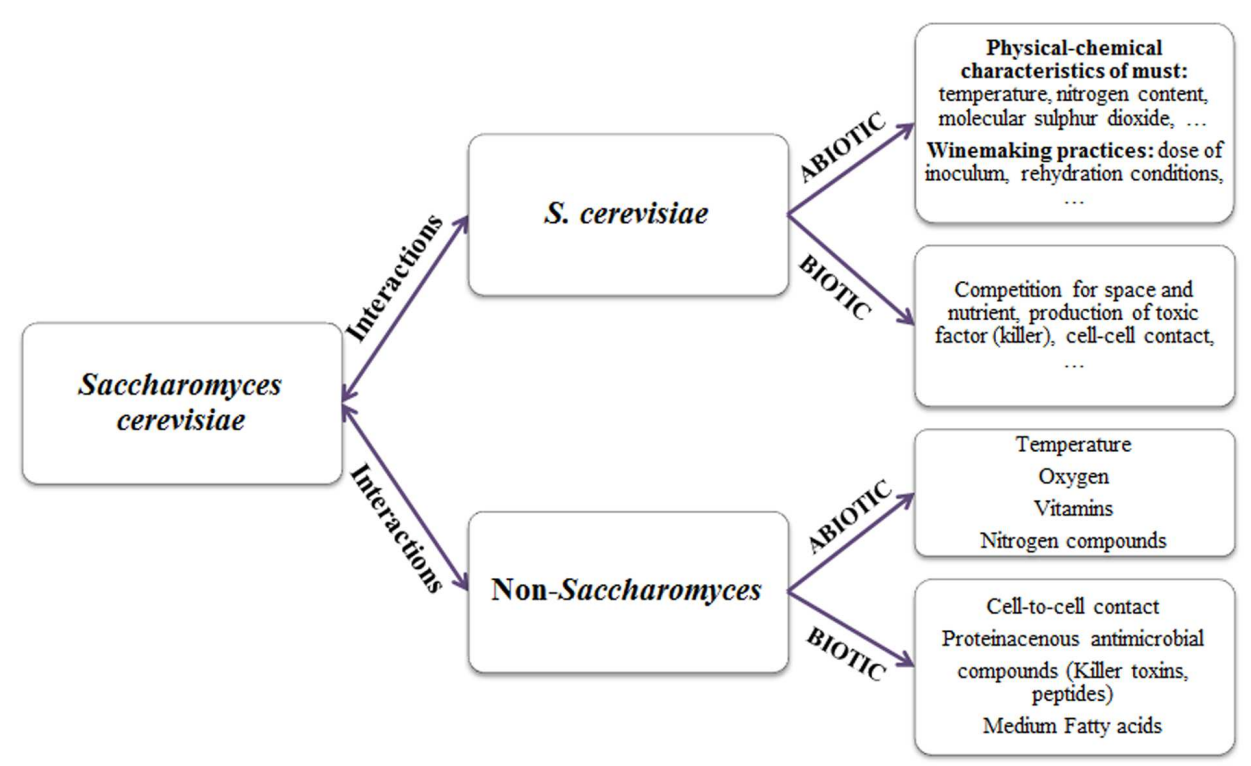

FIGURE 1 | Factors affecting yeast interactions in inoculated wine fermentation.

fermentation, the killer factor is the most studied. Both neutral and sensitive strains do not produce toxins, but the neutrals are resistant to their action. The use of selected $S$. cerevisiae strains with the killer factor may be effective in suppressing undesirable wild yeast strains or in avoiding stuck fermentations caused by indigenous killer yeasts. The magnitude of killer effect in wine fermentation depends on: the initial ratio of killer to sensitive strains, the presence of protein adsorbing substances, the environmental conditions and the growth phase of the sensitive cells, the presence of protective neutral yeasts, the susceptibility of sensitive strains to the killer toxins of different yeast strains, the inoculum size and nitrogen availability (Pérez et al., 2001). The killer phenotype seems to be linked to the execution of apoptosis, a form of active cell death, widely used by multicellular organisms, e.g., during development or as a mechanism to remove damaged and/or potentially cancerous cells. Apoptotic machinery has been also reported for S. cerevisiae. The finding of cell death with apoptosis-like features in yeast (Madeo et al., 1997) was unexpected, as a unicellular organism seems to have no advantages in committing suicide. As the exposure to killer toxins produced and secreted by concurring killer strains is another natural cell death situation for yeast, some authors (Reiter et al., 2005) investigated if killer toxins are able to induce the apoptotic process and if apoptosis is responsible for cell death in the presence of moderate or low toxin concentrations, closely reflecting the situation in the natural yeast habitat. The results showed that killer toxin action can trigger two modes of cell death. Under high toxin concentrations induction of apoptosis plays a minor role, whereas under moderate or low toxin doses, resembling the natural environment of toxin-secreting killer yeasts, induction of apoptosis might play an important role in efficient toxinmediated cell killing. In this situation, it might be of general importance for a toxin-secreting yeast to induce apoptosis in competing yeast cells, in particular at toxin concentrations that are per se too low to kill via the toxin's primary mode of action.

Another biotic factor involved in the interaction among different yeasts is due to a cell-to-cell contact mechanism. Perrone et al. (2013) investigated S. cerevisiae intraspecies competition during wine fermentations, in which the cells of the different strains were mixed or kept separated. In cofermentation, only the dominant strain was detected, whereas in bio-reactor, in which the cells from the two different strains were kept separate by a membrane and the strains did not sense each other, dominance did not take place. These authors postulated that growth arrest was due to cell-to-cell contact or microenvironment contact; in these conditions, cells compete for space when in high densities and in cell-to-cell contact.

\section{NON-Saccharomyces/Saccharomyces INTERACTIONS}

Controlled multistarter fermentations are characterized by complex interaction between non-Saccharomyces and Saccharomyces strains (Ciani et al., 2010; Ciani and Comitini, 2015). Although the physiological and biochemical basis for the overall antagonistic interactions among wine yeasts are still unclear, environmental factors, the production of bioactive yeast metabolites or yeast-yeast interaction could be involved (Figure 1). In this context, the management of mixed fermentations, such as cell concentration, inoculation modalities (pure or mixed fermentation), and timing of sequential fermentations, require more knowledge on environmental factors and metabolic activities influencing the yeast interactions. 
TABLE 1 | Main killer toxins involved in wine making.

\begin{tabular}{|c|c|c|c|c|}
\hline Killer yeast & Killer toxin & Sensitive strain & Applicative indications & Reference \\
\hline $\begin{array}{l}\text { Saccharomyces cerevisiae } \\
\text { strain "Prise de mousse" }\end{array}$ & K2 type & Saccharomyces cerevisiae & Control of S. cerevisiae wild strains & Shimizu, 1993 \\
\hline Saccharomyces cerevisiae & K2 type & Saccharomyces cerevisiae & Enhance autolysis in Sparkling wine & Todd et al., 2000 \\
\hline Tetrapisispora phaffii & Kpkt & Hanseniaspora/Kloeckera & Control of "apiculate" yeast & Comitini and Ciani, 2010 \\
\hline Kluyveromyces wickerhamii & Kwkt & Dekkera/Brettanomyces & Anti-Brett activity & Comitini et al., 2004 \\
\hline Wickerhamomyces anomalus & Pikt & Dekkera/Brettanomyces & Anti-Brett activity & Comitini et al., 2004 \\
\hline Pichia membranifaciens & PMKT2 & Dekkera/Brettanomyces & Anti-Brett activity & Santos et al., 2009 \\
\hline Torulaspora delbrueckii & Kbarr-1 & S. cerevisiae killer strains & Broad anti-wine yeast activity & Ramírez et al., 2015 \\
\hline Torulaspora delbrueckii & TdKT & Pichia and Brettanomyces/Dekkera & Spoilage wine yeasts & Villalba et al., 2016 \\
\hline
\end{tabular}

\section{Management and Yeast Interactions}

The management of mixed fermentation strongly influences the dominance and persistence of yeast species. Several investigations showed that in non-Saccharomyces/S. cerevisiae co-culture at ratio $1: 1$, the growth of $S$. cerevisiae was not affected by the coinoculated yeast, that more or less quickly disappeared. However, at higher inoculation ratio (100:1), Lachancea thermotolerans and Saccharomycodes ludwigii, Hanseniaspora uvarum, and H. guilliermondii persisted for more time, while Candida zemplinina (synonym Starmerella bacillaris) showed a lower competitiveness, increasing its persistence only when the ratio was 10000:1 (Perez-Nevado et al., 2006; Comitini et al., 2011; Domizio et al., 2011). To enhance the competitiveness of non-Saccharomyces strains, the sequential fermentation is a useful inoculation modality. The timing of second inoculation, mimicked the spontaneous fermentation, allows to obtain a synergistic interaction between non-Saccharomyces and S. cerevisiae strains. Several works, investigating on sequential fermentation using various timing of second inoculation, highlighted the actual presence and contribution of several nonSaccharomyces species (Andorrà et al., 2012; Azzolini et al., 2012; Gobbi et al., 2013; Canonico et al., 2015).

\section{Abiotic Factors}

As generally recognized, the increasing concentration of ethanol during the fermentation process, is the main factor that determines the dominance of $S$. cerevisiae toward nonSaccharomyces yeasts (Pretorius, 2000). Indeed, S. cerevisiae strains possess a higher ethanol tolerance than nonSaccharomyces yeasts. On the other hand, the competition for nutrients, such as vitamins and nitrogen compounds, contributes to modulate the presence and dominance of yeasts species during wine fermentation (Liu et al., 2015). Oxygen availability affects growth and fermentation performance of wine yeasts having a selective action among the various yeast species (Ciani and Comitini, 2006; Brandam et al., 2013; Jolly et al., 2014; Taillander et al., 2014). Indeed, S. cerevisiae and non-Saccharomyces wine yeasts exhibit a different behavior in presence of a low oxygen content. In particular, in anaerobic conditions, S. cerevisiae is able to grow quickly (Hansen et al., 2001) while non-Saccharomyces yeasts belonging to Hanseniaspora, Kloeckera, and Torulaspora genera, grow poorly under the same conditions (Visser et al., 1990). The low competitiveness exhibited by L. thermotolerans and Torulaspora delbrueckii could be in part explained by their reduced tolerance to scarce oxygen availability (Nissen et al., 2004).

Another important nutrient factor, that could influence the behavior and the dominance of yeast strains in mixed fermentation, is the availability of nitrogen source and vitamins. In general, when non-Saccharomyces species grow early during wine fermentation (e.g., spontaneous fermentation), these species can consume amino acids and vitamins, thus limiting S. cerevisiae growth (Bisson, 1999; Fleet, 2003). A competition for nutrients was reported by Medina et al. (2012), while Taillander et al. (2014) reported a sluggish fermentation in $48 \mathrm{~h}$ sequential fermentation of $T$. delbrueckii/S. cerevisiae due to nitrogen exhaustion by T. delbrueckii. In a recent work, Kemsawasd et al. (2015) indicated that different nitrogen sources had different impacts on the growth and fermentation behavior of $S$. cerevisiae and the other main non-Saccharomyces fermenting wine yeasts. On the other hand, non-Saccharomyces species and particularly yeast strains belonging to Hanseniaspora and Metschnikowia genera can contribute to enrichment of the medium as a nitrogen source by their proteolytic activity (Dizzy and Bisson, 2000).

Also the competition for other nutrients may influence the interactions between S. cerevisiae and non-Saccharomyces. In this context, several positive and negative interactions have been reported regarding substrate limitation or depletion (Ivey et al., 2013; Oro et al., 2014). Among the environmental factors, temperature has an important role in yeast interactions and dominance of the fermentation process. The high temperature in synergy with increasing ethanol concentration affects membrane permeability and integrity. In this contest, some works indicated that ethanol does not provide a clear advantage to $S$. cerevisiae at low temperature $\left(<15^{\circ} \mathrm{C}\right)$. Indeed, the persistence and/or the dominance of non-Saccharomyces over S. cerevisiae at low temperature has been recognized (Gao and Fleet, 1988; Ciani and Comitini, 2006). A study on the interaction between co-inoculated $S$. cerevisiae and $L$. thermotolerans fermentation, showed that the antagonistic effect between these two yeasts were temperature dependent (Gobbi et al., 2013). A recent study, on the evolution of ecological dominance of yeast species, confirmed that temperature of fermentation plays an important role on the ability of S. cerevisiae to dominate high-sugar environments (Williams et al., 2015). 


\section{Biotic Factors}

The metabolic activities, that influence the controlled multistarter fermentations, could be grouped in antimicrobial molecules and cell-to-cell contact mechanism. Albergaria et al. (2010), investigating on the nature of the toxic compounds produced by $S$. cerevisiae responsible of the early death of $H$. guilliermondii during mixed fermentations, found that the killing effect was due to proteinaceous compounds. In particular, the active proteinaceous compounds exhibited a very low molecular weight that ranged from 2 to $10 \mathrm{kDa}$ and showed a wide antimicrobial spectrum against strains of Kluyveromyces marxianus, L. thermotolerans, and T. delbrueckii. Further investigations demonstrated that S. cerevisiae during alcoholic fermentation secretes antimicrobial peptides, corresponding to fragments of the glyceraldehyde 3phosphate dehydrogenase enzyme, that are active against a wide spectrum of wine yeasts including Dekkera bruxellensis and the malolactic bacterium Oenococcus oeni (Branco et al., 2014, 2015). Among the antimicrobial compounds, killer toxins are certainly involved on the interactions in mixed fermentations. An example of yeast interaction during mixed fermentations non-Saccharomyces/S. cerevisiae yeasts due to the action of killer toxin was described by Comitini and Ciani (2010). Another application of non-Saccharomyces killer yeasts in sequential fermentation with $S$. cerevisiae starter strain was the use of Wickerhamomyces anomalus and Kluyveromyces wickerhamii to control Dekkera/Brettanomyces spoilage yeasts (Comitini et al., 2004). The main killer toxins involved in wine fermentation are showed in Table 1.

Together with proteinaceous antimicrobial compounds, medium fatty acids, produced during alcoholic fermentation above a given threshold, could exhibit inhibitory actions toward S. cerevisiae and/or other species (Viegas et al., 1989).

Cell-to-cell contact is the other mechanism that could influence the interaction among yeast strains. Nissen et al. (2003) demonstrated this phenomenon carrying out single- and mixed-culture fermentations using both $L$. thermotolerans and T. delbrueckii with S. cerevisiae.

\section{REFERENCES}

Albergaria, H., Francisco, D., Gori, K., Arneborg, N., and Girio, F. (2010). Saccharomyces cerevisiae CCMI 885 secretes peptides that inhibit the growth of some non-Saccharomyces wine-related strains. Appl. Microbiol. Biotechnol. 86, 965-972. doi: 10.1007/s00253-009-2409-6

Andorrà, I., Berradre, M., Mas, A., Esteve-Zarzoso, B., and Guillamón, J. M. (2012). Effect of mixed culture fermentations on yeast populations and aroma profile. LWT Food Sci. Technol. 49, 8-13. doi: 10.1016/j.lwt.2012. 04.008

Arroyo-López, F. N., Peréz-Través, L., Querol, A., and Barrio, E. (2011). Exclusion of Saccharomyces kudriavzevii from a wine model system mediated by Saccharomyces cerevisiae. Yeast 28, 423-435. doi: 10.1002/ yea. 1848

Azzolini, M., Fedrizzi, B., Tosi, E., Finato, F., Vagnoli, P., Scrinzi, C., et al. (2012). Effects of Torulaspora delbrueckii and Saccharomyces cerevisiae mixed cultures on fermentation and aroma of Amarone. Eur. Food Res. Technol. 235, 303-313. doi: $10.1007 /$ s00217-012-1762-3
Similarly, Renault et al. (2013), investigating on the interaction between $S$. cerevisiae and $T$. delbrueckii in a new doublecompartment fermenter, found that physical contact between $S$. cerevisiae and T. delbrueckii induced a rapid death of the nonSaccharomyces yeast. In contrast, when physically separated from S. cerevisiae, T. delbrueckii maintained its viability and metabolic activity determining a marked impact on $S$. cerevisiae growth and viability. More recently, Kemsawasd et al. (2015) clarified the phenomenon of the early death of $L$. thermotolerans during anaerobic, mixed-culture fermentations with $S$. cerevisiae. They found that this phenomenon was caused by a combination of cell-to-cell contact and antimicrobial peptides.

\section{CONCLUSION AND FUTURE PERSPECTIVES}

Investigations on yeast interactions in pure and mixed inoculated fermentation in winemaking are in fast development. Further knowledge on yeast interactions needs to manage the inoculated fermentations, to assure the dominance of inoculated strain in pure fermentation and the contribution of each inoculated yeast in mixed fermentation. In addition, these studies on yeasts interactions will contribute to control undesirable or spoilage microflora avoiding or reducing the use of synthetic antimicrobial compounds, such as sulfur dioxide. As reported above, several features influence the yeast interactions in wine fermentation. To obtain a more complete picture on yeast interaction in inoculated fermentation (pure and mixed with non-Saccharomyces) a multifactorial approach using "omics" methodologies should be planned.

\section{AUTHOR CONTRIBUTIONS}

MC, AC, FC, and PR conceived the idea and outline of the review, LC and GS contributed to the graphical elaboration of data. All authors contributed to writing specific sections and approved the final version of the manuscript.

Barrajón, N., Arévalo-Villena, M., Rodríguez-Aragón, L. J., and Briones, A. (2009). Ecological study of wine yeast in inoculated vats from La Mancha region. Food Control 20, 778-783. doi: 10.1016/j.foodcont.2008.10.002

Barrajón, N., Arévalo-Villena, M., Úbeda, J., and Briones, A. (2010). “Competition between spontaneous and commercial yeasts in winemaking: study of possible factors involved," in Communicating Current Research and Education Topics and Trends in Applied Microbiology and Microbiology Book Series Vol. 2, ed. A. Mendez-Vilas (Badajoz: Formatex Research Center), 1035-1041.

Barrajón, N., Arévalo-Villena, M., Úbeda, J., and Briones, A. (2011). Enological properties in wild and commercial Saccharomyces cerevisiae yeasts: relationship with competition during alcoholic fermentation. World J. Microbiol. Biotechnol. 27, 2703-2710. doi: 10.1007/s11274-011-0744-0

Bauer, F. F., and Pretorius, I. S. (2000). Yeast stress response and fermentation efficiency: how to survive the making of wine. South Afr. J. Enol. Vitic. 21, 27-51.

Bisson, L. F. (1999). Stuck and sluggish fermentations. Am J. Enol Vitic. 50, 107-119.

Branco, P., Francisco, D., Chambon, C., Hébraud, M., Arneborg, N., and Almeida, M. G. (2014). Identification of novel GAPDH-derived antimicrobial 
peptides secreted by Saccharomyces cerevisiae and involved in wine microbial interactions. Appl. Microbiol. Biotechnol. 98, 843-853. doi: 10.1007/s00253-0135411-y

Branco, P., Viana, T., Albergaria, H., and Arneborg, N. (2015). Antimicrobial peptides (AMPs) produced by Saccharomyces cerevisiae induce alterations in the intracellular $\mathrm{pH}$, membrane permeability and culturability of Hanseniaspora guilliermondii cells. Int. J. Food Microbiol. 16, 205-212. doi: 10.1016/j.ijfoodmicro.2015.04.015

Brandam, C., Lai, Q. P., Julien-Ortiz, A., and Taillandier, P. (2013). Influence oxygen of alcoholic fermentation by a wine strain of Torulaspora delbrueckii: kinetics and carbon mass balance. Biosci. Biotechnol. Biochem. 77, 1848-1853. doi: $10.1271 /$ bbb. 130228

Canonico, L., Comitini, F., and Ciani, M. (2015). Influence of vintage and selected starter on Torulaspora delbrueckii/Saccharomyces cerevisiae sequential fermentation. Eur. Food Res. Technol. 241, 827-833. doi: 10.1007/s00217-0152507-x

Capece, A., Romaniello, R., Poeta, C., Siesto, G., Massari, C., Pietrafesa, R., et al. (2011). Control of inoculated fermentations in wine cellars by mitochondrial DNA analysis of starter yeast. Ann. Microbiol. 61, 49-56. doi: 10.1007/s13213010-0087-3

Capece, A., Romaniello, R., Siesto, G., Pietrafesa, R., Massari, C., Poeta, C., et al. (2010). Selection of indigenous Saccharomyces cerevisiae strains for Nero d'Avola wine and evaluation of selected starter implantation in pilot fermentation. Int. J. Food Microbiol. 144, 187-192. doi: 10.1016/j.ijfoodmicro.2010.09.009

Capece, A., Siesto, G., Romaniello, R., Lagreca, V. M., Pietrafesa, R., Calabretti, A., et al. (2013). Assessment of competition in wine fermentation among wild Saccharomyces cerevisiae strains isolated from Sangiovese grapes in Tuscany region. LWT-Food Sci. Technol. 54, 485-492. doi: 10.1016/j.lwt.2013.07.001

Casey, G. P., Magnus, C. A., and Ingledew, W. M. (1984). High gravity brewing: effects of nutrition on yeast composition, fermentative ability and alcohol production. Appl. Environ. Microbiol. 48, 639-646.

Cheraiti, N., Guezenec, S., and Salmon, J.-M. (2005). Redox interactions between Saccharomyces cerevisiae and Saccharomyces uvarum in mixed culture under enological conditions. Appl. Environ. Microbiol. 71, 255-260. doi: 10.1128/AEM.71.1.255-260.2005

Ciani, M., and Comitini, F. (2006). Influence of temperature and oxygen concentration on the fermentation behavior of Candida stellata in mixed fermentation with Saccharomyces cerevisiae. World J. Microbiol. Biotechnol. 22, 619-623. doi: 10.1007/s11274-005-9080-6

Ciani, M., and Comitini, F. (2015). Yeast interactions in multi-starter wine fermentation. Curr. Opin. Food Sci. 1, 1-6. doi: 10.1016/j.cofs.2014.07.001

Ciani, M., Comitini, F., Mannazzu, I., and Domizio, P. (2010). Controlled mixed culture fermentation: a new perspective on the use of non-Saccharomyces yeasts in winemaking. FEMS Yeast Res. 10, 123-133. doi: 10.1111/j.15671364.2009.00579.x

Comitini, F., and Ciani, M. (2010). The zymocidial activity of Tetrapisispora phaffii in the control of Hanseniaspora uvarum during the early stages of winemaking. Lett. Appl. Microbiol. 50, 50-56. doi: 10.1111/j.1472-765X.2009. 02754.x

Comitini, F., De Ingeniis, J., Pepe, L., Mannazzu, I., and Ciani, M. (2004). Pichia anomala and Kluyveromyces wickerhamii killer toxins as new tools against Dekkera/Brettanomyces spoilage yeasts. FEMS Microbiol. Lett. 238, 235-240. doi: 10.1111/j.1574-6968.2004.tb09761.x

Comitini, F., Gobbi, M., Domizio, P., Romani, C., Lencioni, L., Mannazzu, I., et al. (2011). Selected non-Saccharomyces wine yeasts in controlled multi starter fermentations with Saccharomyces cerevisiae. Food Microbiol. 28, 873-882. doi: 10.1016/j.fm.2010.12.001

Dizzy, M., and Bisson, L. F. (2000). Proteolytic activity of yeast strains during grape juice fermentation. Am. J. Enol. Vitic. 51, 155-167. doi: 10.1007/s10482-0150578-0

Domizio, P., Romani, C., Lencioni, L., Comitini, F., Gobbi, M., Mannazzu, I., et al. (2011). Outlining a future for non-Saccharomyces yeasts: selection of putative spoilage wine strains to be used in association with Saccharomyces cerevisiae for grape juice fermentation. Int. J. Food Microbiol. 147, 170-180. doi: 10.1016/j.ijfoodmicro.2011.03.020

Duarte, F. L., Claudia Alves, A., Alemão, M. F., and Baleiras-Couto, M. M. (2013). Influence of red wine fermentation oenological additives on inoculated strain implantation. World J. Microbiol. Biotechnol. 29, 1139-1144. doi: 10.1007/s11274-013-1272-x

Fleet, G. H. (2003). Yeast interactions and wine flavor. Int. J. Food Microbiol. 86, 11-22. doi: 10.1016/S0168-1605(03)00245-9

Gao, C., and Fleet, G. H. (1988). The effects of temperature and $\mathrm{pH}$ on the ethanol tolerance of the wine yeasts, Saccharomyces cerevisiae, Candida stellata and Kloeckera apiculata. J. Appl. Bacteriol. 65, 405-410. doi: 10.1111/j.13652672.1988.tb01909.x

García-Ríos, E., Gutiérrez, A., Salvadó, Z., Arroyo-López, F. N., and Guillamon, M. (2014). The fitness advantage of commercial wine yeasts in relation to the nitrogen concentration, temperature, and ethanol content under microvinification conditions. Appl. Environ. Microbiol. 80, 704-713. doi: 10.1128/AEM.03405-13

Gobbi, M., Comitini, F., Domizio, P., Romani, C., Lencioni, L., Mannazzu, I., et al. (2013). Lachancea thermotolerans and Saccharomyces cerevisiae in simultaneous and sequential co-fermentation: a strategy to enhance acidity and improve the overall quality of wine. Food Microbiol. 33, 271-281. doi: 10.1016/j.fm.2012.10.004

Hansen, E. H., Nissen, P., Sommer, P., Nielsen, J. C., and Arneborg, N. (2001). The effect of oxygen on the survival of non-Saccharomyces yeasts during mixed culture fermentations of grape juice with Saccharomyces cerevisiae. J. Appl. Microbiol. 91, 541-547. doi: 10.1046/j.1365-2672.2001. 01426.x

Howell, K. S., Cozzolino, D., Bartowsky, E. J., Fleet, G. H., and Henschke, P. A. (2006). Metabolic profiling as a tool for revealing Saccharomyces interactions during wine fermentation. FEMS Yeast Res. 6, 91-101. doi: 10.1111/j.15671364.2005.00010.x

Ivey, M., Massel, M., and Phister, T. G. (2013). Microbial interactions in food fermentations. Annu. Rev. Food Sci. Technol. 4, 141-162. doi: 10.1146/annurevfood-022811-101219

Jolly, N. P., Varela, C., and Pretorius, I. S. (2014). Not your ordinary yeast: non-Saccharomyces yeast in wine production uncovered. FEMS Yeast Res. 14, 215-237. doi: 10.1111/1567-1364.12111

Kemsawasd, V., Viana, T., Ardo, Y., and Arneborg, N. (2015). Influence of nitrogen sources on growth and fermentation performance of different wine yeast species during alcoholic fermentation. Appl. Microbiol. Biotechnol. 99, 10191-10207. doi: 10.1007/s00253-015-6835-3

King, E. S., Swiegers, J. H., Travis, B., Francis, I. L., Bastian, S. E. P., and Pretorius, I. S. (2008). Coinoculated fermentations using Saccharomyces yeasts affect the volatile composition and sensory properties of Vitis vinifera L. cv. Sauvignon Blanc wines. J. Agric. Food Chem. 56, 10829-10837. doi: 10.1021/ jf801695h

Liu, Y., Rousseaux, S., Tourdot-Mareìchal, R., Sadoudi, M., Gougeon, R., SchmittKopplin, P., et al. (2015). Wine microbiome, a dynamic world of microbial interactions. Crit. Rev. Food Sci. Nutr. doi: 10.1080/10408398.2014.983591 [Epub ahead of print].

Lucero, P., Peñalver, E., Moreno, E., and Lagunas, R. (2000). Internal trehalose protects endocytosis from inhibition by ethanol in Saccharomyces cerevisiae. Appl. Environ. Microbiol. 66, 4456-4461. doi: 10.1128/AEM.66.10.44564461.2000

Madeo, F., Frohlich, E., and Frohlich, K. U. (1997). A yeast mutant showing diagnostic markers of early and late apoptosis. J. Cell Biol. 139, 729-734. doi: 10.1083/jcb.139.3.729

Medina, K., Boido, E., Dellacassa, E., and Carrau, F. (2012). Growth of nonSaccharomyces yeasts effects nutrient availability for Saccharomyces cerevisiae during wine fermentation. Int. J. Food Microbiol. 157, 245-250. doi: 10.1016/j.ijfoodmicro.2012.05.012

Nissen, P., Nielsen, D., and Arneborg, N. (2003). Viable Saccharomyces cerevisiae cells at high concentrations cause early growth arrest of non-Saccharomyces yeasts in mixed cultures by a cell-cell contact-mediated mechanism. Yeast 20, 331-341. doi: 10.1002/yea.965

Nissen, P., Nielsen, D., and Arneborg, N. (2004). The relative glucose uptake abilities of non-Saccharomyces yeasts play a role in their coexistence with Saccharomyces cerevisiae in mixed cultures. Appl. Microbiol. Biotechnol. 64, 543-550. doi: 10.1007/s00253-003-1487-0

Oro, L., Ciani, M., and Comitini, F. (2014). Antimicrobial activity of Metschnikowia pulcherrima on wine yeasts. J. Appl. Microbiol. 116, 1209-1217. doi: 10.1111/jam. 12446 
Pérez, F., Ramírez, M., and Regodón, J. A. (2001). Influence of killer strains of Saccharomyces cerevisiae on wine fermentation. Antonie Van Leeuwenhoek 79, 393-399. doi: 10.1023/A:1012034608908

Perez-Nevado, F., Albergaria, H., Hogg, T., and Girio, F. (2006). Cellular death of two non-Saccharomyces wine-related yeasts during mixed fermentation with Saccharomyces cerevisiae. Int. J. Food Microbiol. 108, 336-345. doi: 10.1016/j.ijfoodmicro.2005.12.012

Perrone, B., Giacosa, S., Rolle, L., Cocolin, L., and Rantsiou, K. (2013). Investigation of the dominance behavior of Saccharomyces cerevisiae strains during wine fermentation. Int. J. Food Microbiol. 165, 156-162. doi: 10.1016/j.ijfoodmicro.2013.04.023

Pretorius, I. S. (2000). Tailoring wine yeast for the new millennium: novel approaches to the ancient art of winemaking. Yeast 16, 675-729. doi: 10.1002/1097-0061(20000615)16:8<675::AID-YEA585>3.0.CO;2-B

Ramírez, M., Velázquez, R., Maqueda, M., López-Piñeiro, A., and Ribas, J. C. (2015). A new wine Torulaspora delbrueckii killer strain with broad antifungal activity and its toxin-encoding double-stranded RNA virus. Front. Microbiol. 6:983. doi: $10.3389 /$ fmicb.2015.00983

Reiter, J., Herker, E., Madeo, F., and Schmitt, M. J. (2005). Viral killer toxins induce caspase-mediated apoptosis in yeast. J. Cell. Biol. 168, 353-358. doi: 10.1083/jcb.200408071

Renault, P. E., Albertin, W., and Bely, M. (2013). An innovative tool reveals interaction mechanisms among yeast populations under oenological conditions. Appl. Microbiol. Biotechnol. 97, 4105-4119. doi: 10.1007/s00253012-4660-5

Rodriguez-Porrata, B., Novo, M., Guillamon, J., Rozes, N., Mas, A., and Otero, R. C. (2008). Vitality enhancement of the rehydrated active dry wine yeast. Int. J. Food Microbiol. 126, 116-122. doi: 10.1016/j.ijfoodmicro.2008.05.016

Santos, A., San Mauro, M., Bravo, E., and Marquina, D. (2009). PMKT2, a new killer toxin from, and its promising biotechnological properties for control of the spoilage yeast Brettanomyces bruxellensis. Microbiology 155, 624-634. doi: 10.1099/mic.0.023663-0

Shimizu, K. (1993). "Killer yeasts," in Wine Microbiology and Biotechnology, ed. G. H. Fleet (Chur: Harwood Academic), 243-264.

Taillander, P., Lai, Q. P., Julien-Ortiz, A., and Brandam, C. (2014). Interaction between Torulaspora delbrueckii and Saccharomyces cerevisiae in wine fermentation: influence of inoculation and nitrogen content. World J. Microbiol. Biotechnol. 30, 1959-1967. doi: 10.1007/s11274-014-1618-Z
Todd, B. E., Fleet, G. H., and Henschke, P. A. (2000). Promotion of autolysis through the interaction of killer and sensitive yeasts: potential application in sparkling wine production. Am. J. Enol. Vitic. 51, 65-72. doi: 10.1023/A:1012027718701

Torija, M. J., Rozès, N., Poblet, M., Guillamón, J. M., and Mas, A. (2003). Effects of fermentation temperature on the strain population of Saccharomyces cerevisiae. Int. J. Food Microbiol. 80, 47-53. doi: 10.1016/S0168-1605(02) 00144-7

Viegas, C. A., Rosa, M. F., Sá-Correia, I., and Novais, J. M. (1989). Inhibition of yeast growth by octanoic and decanoic acids produced during ethanolic fermentation. Appl. Environ. Microbiol. 55, 210-221.

Vigentini, I., Fabrizio, V., Faccincani, M., Picozzi, C., Comasio, A., and Foschino, R. (2014). Dynamics of Sacharomyces cerevisiae populations in controlled and spontaneous fermentations for Franciacorta D.O.C.G. base wine production. Ann. Microbiol. 64, 639-651. doi: 10.1007/s13213-0130697-7

Villalba, M. L., Susana Sáez, J., del Monaco, S., Lopes, C. A., and Sangorrín, M. P. (2016). TdKT, a new killer toxin produced by Torulaspora delbrueckii effective against wine spoilage yeasts. Int. J. Food Microbiol. 217, 94-100. doi: 10.1016/j.ijfoodmicro.2015.10.006

Visser, W., Scheffers, W. A., Batenburg-Van Der Vegte, W. H., and Van Dijken, J. P. (1990). Oxygen requirements of yeasts. Appl. Environ. Microbiol. 56, 3785-3792.

Williams, K. M., Liu, P., and Fay, J. C. (2015). Evolution of ecological dominance of yeast species in high-sugar environments. Evolution 69, 2079-2095. doi: $10.1111 /$ evo. 12707

Conflict of Interest Statement: The authors declare that the research was conducted in the absence of any commercial or financial relationships that could be construed as a potential conflict of interest.

Copyright (C) 2016 Ciani, Capece, Comitini, Canonico, Siesto and Romano. This is an open-access article distributed under the terms of the Creative Commons Attribution License (CC BY). The use, distribution or reproduction in other forums is permitted, provided the original author(s) or licensor are credited and that the original publication in this journal is cited, in accordance with accepted academic practice. No use, distribution or reproduction is permitted which does not comply with these terms. 